\title{
Twelve Years of Kawasaki Disease in Portugal
}

\section{Epidemiology in Hospitalized Children}

\author{
Fátima F. Pinto, MD, *† Sérgio Laranjo, MD, * Miguel Mota Carmo, MD, PhD, $\neq$ Maria João Brito, MD, $\S$ \\ and Rui Cruz Ferreira, MD广t
}

\begin{abstract}
Background: Kawasaki disease (KD) is the leading cause of acquired heart disease in developed countries. Reported incidences vary worldwide but incidence of KD has not been established in Portugal.

Aim: The aims of the study were to describe the epidemiologic characteristics and estimate incidence rates of KD among hospitalized children in Portugal. Methods: This study was a descriptive, population-based study, which used hospital discharge records of patients $<20$ years of age diagnosed with $\mathrm{KD}$ from the Hospital Register database for 2000-2011. Incidence rates were calculated using the number of KD patients and corresponding National census data.

Results: There were 533 hospitalizations of 470 patients with $\mathrm{KD}$ as the primary diagnosis in Portugal, 63 hospitalizations were transfers of patients between hospitals and there were no relapses. The mean age at admission was 2.8 years, with male predominance (male-to-female ratio: 1.6:1). Children $<5$ years and infants $<1$ year represented $83 \%$ and $23 \%$ of all the patients admitted, respectively. Mean annual incidence was 6.5 per 100,000 children $<5$ years, 4.5 per 100,000 infants $<1$ year and 7.8 per 100,000 infants 1-4 years. We found considerable differences between national territorial regions, with majority of cases in most dense regions. The mean length of hospital stay was 9 days, and the incidence peaked in spring $(35 \%)$ and spring/winter $(63 \%)$. Coronary aneurysms were reported in $8.5 \%$ of patients with a higher male-to-female ratio (3.4:1) and a lower mean age (1.93 years). Reported mortality was $0.4 \%$.

Conclusions: This is the first large-scale epidemiologic study of KD in Portugal. The highest incidences occurred among male children 1-4 years of age and in spring/winter.
\end{abstract}

Key Words: Kawasaki disease, epidemiology, incidence, Portugal

(Pediatr Infect Dis J 2017;36:364-368)

$\mathrm{K}$ awasaki disease (KD) is an acute febrile illness with multisystemic vasculitis that predominantly occurs in children under 5 years of age and has a male predominance. The disease was first described in 1967, in Japan by Tomisaku Kawasaki, and has now been reported worldwide in all ethnic and racial groups but with significant differences in incidence rates. ${ }^{1-6}$

$\mathrm{KD}$ is the leading cause of acquired heart disease in developed countries. The main complication of this rare disease is cardiac involvement and development of coronary artery

Accepted for publication November 25, 2016.

From the *Pediatric Cardiology Department, Hospital de Santa Marta, CHLC, $\uparrow$ National Program of Cerebro and Cardiovascular Diseases, Direcção Geral de Saúde, \$Cardiology Department, Hospital de Santa Marta, CHLC, and §nfectious Diseases Unit, Hospital de Dona Estefania, CHLC, Lisbon, Portugal.

The authors have no funding or conflicts of interest to disclose.

Address for correspondence: Fátima F. Pinto, MD, Hospital de Santa Marta, Department of Paediatric Cardiology, Rua de Santa Marta, no 50, 1269-024 Lisboa, Portugal. E-mail: mariafatimafpinto@gmail.com.

Supplemental digital content is available for this article. Direct URL citations appear in the printed text and are provided in the HTML and PDF versions of this article on the journal's website (www.pidj.com).

Copyright (C) 2016 Wolters Kluwer Health, Inc. All rights reserved.

ISSN: 0891-3668/17/3604-0364

DOI: $10.1097 /$ INF.0000000000001444 aneurysms (CAA), which can evolve into stenosis and occlusion, which are the leading cause of myocardial infarction in children. The treatment with high-dose intravenous immunoglobulin within 10 days after disease onset changes its outcome, decreasing significantly the incidence of CAA up to $25 \%$ in untreated patients and up to $5 \%-15 \%$ in patients who were adequately treated. ${ }^{6-9}$

The etiology of the disease remains unknown, despite 4 decades of research. Antecedent respiratory illness and exposure to rug cleaning have been previously associated with KD. Neither of these or other environmental risk factors have been consistently identified as contributors to the disease. ${ }^{8,9}$

The leading hypothesis is that KD reflects an abnormal inflammatory response to one or more infectious triggers and environment factors in genetically susceptible individuals. The genetic predisposition is supported by the striking difference in annual incidence between children of Asian (69-222 per 100,000 children $<5$ years of age) and European descent (4-15 per 100,000 children $<5$ years of age), which remains higher when Asian descendent children live in occidental countries. ${ }^{9-13}$

The first case of KD in Portugal was reported in $1981^{14}$; to date several case reports and small retrospective studies have been published in Portugal, assuming incidence rates on limited and biased data that do not reflect the national incidence. In 2001, the Portuguese Pediatric Society started a Pediatric surveillance unit for KD. Although many clinicians have reported their cases, it was considered that the adherence to the surveillance was suboptimal, and it was not possible to complete an epidemiologic study. ${ }^{14-20}$

Recently, we started an extended study protocol for KD patients follow-up, specially focused on long-term cardiovascular sequelae, endothelial function and precursors of atherosclerosis evaluation. The lack of accurate data on epidemiology and incidence of KD in Portugal was an important factor, which strongly supports this study.

Several previous studies have demonstrated that hospital discharge data are suitable for KD epidemiology surveillance and for providing estimates of KD incidence, once the vast majority of children with KD are hospitalized worldwide and also in Portugal. ${ }^{10,21-24}$ In this study, the authors analyzed data from the national database of hospital discharge diagnostic codes regarding hospitalized children classified with KD code for a period of 12 years. Using these data, we estimated the number of the KD hospitalizations, the number of patients with the disease and the mean annual incidences of KD among children in Portugal.

\section{MATERIALS AND METHODS}

\section{Hospital Discharge Records}

In Portugal, the diagnosis-related groups (DRGs) classification system was officially established in 1990 for obtaining a concise and accurate summary of the case history. This classification system allows a systematic and economic way of collecting the main information included in the case history and checking their quality. This coding system is mandatory and official for every patient discharged from all public hospitals nationwide. The DRGs 
form is coded and includes both clinical and procedural aspects of hospitalization. DRGs are coded using the International Classification of Diseases, 9th revision, Clinical Modification Code system. ${ }^{22}$

In this study, the national DRG database was retrospectively searched for code 446.1 of the International Classification of Diseases, 9th revision, Clinical Modification Code: Kawasaki disease, over the period from 2000 to 2011 . Hospital discharge records data were extracted, and we examined KD-associated hospitalizations by number of patients, age group, gender, outcome, hospital stay and region. Accompanying diagnoses were also analyzed, especially cardiac complications. Because data are based on hospitalization records, some variables (ethnic/race; immunoglobulin administration) were missing. Patients who had more than 1 record for the same episode or were admitted to one hospital and transferred to another were considered only once, and included in the region of the initial admission and the admission age was considered that of the first hospitalization. ${ }^{22}$ The study was approved by the ethics committee of the hospital.

Patients were stratified into 4 groups according to their age of admission: $<5,5-9,10-14$ and 15-19 years of life. Children $<5$ years of age were further stratified into 2 subgroups: $<1$ and $1-4$ years of age. Five of the 7 territorial regions of Portugal were considered: North, Center, Lisbon, Alentejo and Algarve, representing continental regions; data on Atlantic islands of Madeira and Azores were not included.

Hospitalization rates and estimates of annual incidence were expressed per 100,000 children, using the 2011 national census estimates (Instituto Nacional de Estatística-Statistics Portugal) stratified for the same age groups and territorial units; it was possible to evaluate the number of cases per 100,000 inhabitants stratified by age groups, gender and territorial units (Table, Supplemental Digital Content 1, http://links.lww.com/ $\mathrm{INF} / \mathrm{C} 614) .{ }^{23}$

\section{Statistics}

Statistical analysis was performed using the Statistical Package for Social Sciences, version 20.0 (SPSS, Chicago, IL), for Windows. Data are expressed as mean \pm standard deviation (SD), mean with range or number with percentage as appropriate. Descriptive statistics were performed on the demographic characteristics.

\section{RESULTS}

\section{Overall}

During the period from 2000 to 2011, a total of 533 hospitalizations were registered for 470 individuals $<20$ years of age in Portugal on database for hospitalizations of KD patients, 63 hospitalizations were transfers between hospitals and there were no relapses. Of these individuals, 393 patients were stratified into the group with children $<5$ years of age corresponding to $83.4 \%$ of the sample and 109 patients were stratified into the subgroup with children $<1$ year old $(23 \%)$.

The mean age at admission of all patients was 2.8 years (ranged from 2.4 to 3.8 years in 2007 and 2003, respectively). The mean age was lowest in Alentejo (1.7 years) and highest in the North (3.5 years) territorial regions.

Sixty-one percent of patients $(287 / 470)$ were male, ratio $1.6 / 1(P=0.0003)$, ranging from $1.2 / 1$ in the North to 1.8 and $1.7 / 1$ in Center and Lisbon regions, respectively (Table 1 ). Considering the stratified age groups and subgroups, infants $<1$ year of age had the highest male-to-female ratio, 1.8:1, and children $<5$ years of age had a ratio similar to that of the whole sample. The mean age of hospitalization differed between boys and girls, but without statistical significance (27 and 33 months, respectively, $P=0.1$ ).
TABLE 1. Hospitalized Patients With Kawasaki Disease in Portugal; Distribution per Year and Region

\begin{tabular}{lcccccc}
\hline \hline & \multicolumn{5}{c}{ Portuguese Regions } & \\
\cline { 2 - 6 } Year & Alentejo & Algarve & Centro & Lisbon & North & Total (\%) \\
\hline 2000 & 1 & 1 & 5 & 37 & 3 & $47(10.0)$ \\
2001 & 1 & 2 & 3 & 20 & 4 & $30(6.4)$ \\
2002 & 1 & 2 & 8 & 17 & 5 & $33(7.0)$ \\
2003 & 1 & 2 & 4 & 18 & 5 & $30(6.4)$ \\
2004 & 2 & 3 & 9 & 27 & 9 & $50(10.6)$ \\
2005 & & 2 & 7 & 25 & 9 & $43(9.1)$ \\
2006 & 1 & 1 & 8 & 23 & & $33(7.0)$ \\
2007 & 1 & 2 & 5 & 26 & 9 & $43(9.1)$ \\
2008 & & & 9 & 22 & 15 & $46(9.8)$ \\
2009 & 1 & 2 & 8 & 22 & 6 & $39(8.3)$ \\
2010 & 1 & & 6 & 16 & 8 & $31(6.6)$ \\
2011 & & 2 & 10 & 24 & 9 & $45(9.6)$ \\
Total (\%) & $10(2.1)$ & $19(4.0)$ & $82(17.5)$ & $277(58.9)$ & $82(17.5)$ & 470 \\
& & & & & &
\end{tabular}

We also found variations in territorial patient distribution, with the majority of cases in the more populated regions: more than half of the patients were hospitalized in the Lisbon region $(58.9 \%)$; the lowest number of hospitalizations occurred in the south regions of the country (Algarve and Alentejo $2.1 \%$ and $4.0 \%$, respectively); the North and the Center accounted for the identical admission rates of $17.4 \%$.

The mean length of hospital stay was 9 days, ranging from 1 to 110 days; the incidence peaked in spring (35\%) and during spring/winter (63\% of cases). During the study period, there was an average of 39 new patients with KD per year, and 4 peaks of total hospitalized patients: 2000 (47); 2004 (50); 2008 (46) and 2011 (45) (Table 1).

Cardiac involvement was reported in $12.9 \%$ of patients (61 patients), with a male-to-female ratio of $3.1: 1(P=0.001)$ and a mean age of 2.41 years (from 1.5 months to 8 years). The most frequent cardiac lesion was development of coronary aneurysms (code 414.1 ), reported in 40 patients $(8.5 \%)$, followed by pericarditis in 18 patients $(3.8 \%)$, mitral valvulitis in 2 patients $(0.4 \%)$ and supraventricular tachycardia in 1 patient. The vast majority of cases with CAA occurred in children younger than 5 years of age $(n=35$ patients, $87.5 \%$; mean age: 1.93 years; SD: 1.92) and in the subgroup of children $1-4$ years of age $(n=21$ patients, $52.5 \%$; mean age: 1.24 years; SD: 0.98). Gender distribution was significantly different with a male-to-female ratio of $3.4: 1$ in the whole group $(3.7 / 1$ for infants $<1$ year; $3.2 / 1$ and $4 / 1$ for children $1-4$ and 5-9 years of age, respectively). The territorial distribution was similar to that of the general cohort.

There were 2 deaths $(0.4 \%)$ : male infants 14 and 21 months of age died in 2007 and 2011, respectively, in the Lisbon region. The cause of death was attributed to myocardial infarction. Both patients had multiple coronary aneurysms and resistance to conventional treatment.

\section{Incidence Rates}

Based on the Census data from 2011 provided by Statistics Portugal, the mean annual incidences of KD in Portugal were calculated (Table 2). ${ }^{25}$ From 2000 to 2011, the incidence of KD was highest in children younger than 5 years $(6.48$ per 100,000 children; 95\% CI: 7.4-5.6; ranging from 3.8 to 8.3 ), followed by children between 5 and 9 years of age (1.1 per 100,000 children) and almost null for older patients. Considering the general population, the incidence of $\mathrm{KD}$ is 1.9 per 100,000 individuals. 
TABLE 2. Incidence of Kawasaki Disease in Portuguese Population Stratified by Age Groups and Subgroups and by Year

\begin{tabular}{lccccccc}
\hline \hline Year & $<1 \mathrm{yr}$ & $1-4 \mathrm{yr}$ & $<5 \mathrm{yr}$ & $5-9 \mathrm{yr}$ & $10-14 \mathrm{yr}$ & $15-19 \mathrm{yr}$ & Total \\
\hline 2000 & 4.69 & 10.16 & 7.91 & 0.77 & 0.37 & 0.00 & 2.11 \\
2001 & 3.26 & 5.15 & 4.38 & 1.36 & 0.00 & 0.00 & 1.36 \\
2002 & 4.69 & 5.66 & 5.27 & 0.97 & 0.00 & 0.00 & 1.51 \\
2003 & 2.82 & 4.37 & 3.75 & 1.76 & 0.00 & 0.17 & 1.39 \\
2004 & 8.66 & 8.13 & 8.33 & 0.77 & 0.37 & 0.00 & 2.34 \\
2005 & 3.90 & 7.63 & 6.16 & 2.10 & 0.00 & 0.00 & 2.03 \\
2006 & 4.95 & 6.11 & 5.66 & 0.57 & 0.19 & 0.00 & 1.57 \\
2007 & 5.63 & 8.80 & 7.56 & 0.76 & 0.19 & 0.00 & 2.05 \\
2008 & 4.12 & 10.98 & 8.29 & 0.57 & 0.39 & 0.00 & 2.21 \\
2009 & 3.66 & 8.49 & 6.59 & 1.35 & 0.00 & 0.00 & 1.89 \\
2010 & 2.14 & 8.41 & 5.92 & 0.40 & 0.00 & 0.19 & 1.52 \\
2011 & 5.40 & 9.68 & 7.97 & 1.42 & 0.19 & 0.00 & 2.24 \\
Average & 4.49 & 7.80 & 6.48 & 1.07 & 0.14 & 0.09 & 1.85 \\
\hline
\end{tabular}

When we stratified children under 5 years of age into 2 subgroups, infants under 1 year of age and children between 1 and 4 years of age, we obtained an incidence of 4.5 (95\% CI: 5.44-3.54) and 7.8 (95\% CI: 8.97-6.63) per 100,000, respectively.

The incidence of KD was significantly higher in boys, with the highest rate occurring in male infants under 1 year of age (11.4 per 100,000; 95\% CI: 14.32-8.34) when compared with female infants of the same age (6.5 per 100,000; 95\% CI: 7.98-5.02). The male predominance is constant in all age groups, although with smaller differences (Table 3).

The incidence of KD was higher in the regions with a higher density of population, like Lisbon, an exception in the North region. Considering the group of children under 5 years, the highest incidence was in Lisbon region with 13.0 per 100,000 children, followed by Algarve and Center regions with an incidence of 6.3 and 5.2 per 100,000 children, respectively (Table 4).

\section{DISCUSSION}

This is the first large-scale epidemiologic study of KD in Portugal, which provides a national estimate of hospitalizations associated with physician-diagnosed KD among Portuguese children and estimates of patients. This study revealed a mean annual incidence of 6.48 per 100,000 children under 5 years of age from 2000 through 2011. As expected, this incidence is very different from the highest incidences observed in Japan and other Asian countries, which favors the genetic theory for KD etiology. The mean incidence varied between 3.75 and 7.97 during our 12-year study period. These incidences fall within the range from 3.6 to 15.2 reported in other European studies, for Caucasians (Table, Supplemental Digital Content 2, http://links.lww.com/INF/C615 which shows the annual incidence of KD in different European countries). There was some stability in the number of cases per year, with a mean of 39 cases per year, although there was evidence of some periodic peaks of incidence, as other authors have also reported, aspect that supports the infectious etiology. The data of this study also suggest that the incidence of KD has not remarkably changed during the study period, as also reported by other authors. ${ }^{26-36}$

The mean incidence found to occur in the current study could be underestimated, taking into account several factors such as the methodology, the retrospective nature of the coding system and the probability of some cases not being correctly coded. In addition, atypical cases may have been missed because of the public health system in Portugal, where general practitioners examine children before referral to the pediatrician. Although general practitioners follow national guidelines to contact a pediatrician after 5 days of persistent fever (earlier in infants and very young children), missing cases of KD because of unawareness of this rare disease is likely to occur. In addition, pediatricians may also have underdiagnosed KD because of the obvious resemblance with infectious disease and the lack of any specific diagnostic test. We, therefore, believe that the incidence of 6.48 per 100,000 children $<5$ years of age should be taken as a minimum estimate of the true incidence of KD in Portugal.

KD rates were higher in younger children $(6.48$ per 100,000 children under 5 years) with a mean age of 2.8 years; male infants and children are more prone to the disease than female pediatric population with a mean ratio of $1.6: 1$ (varying from $1.8 / 1$ and $1.4 / 1)$. The highest rate occurred in male infants under 1 year of age, with an incidence rate almost double when compared with female infants of the same age (11.4 vs. 6.5 per 100,000).

Cardiac involvement and mortality were also within the expected rates. The incidence of CAA was significantly higher among boys, with a male-to-female ratio of 3.4:1. Coronary aneurysms occurred mainly in male children under 5 years of age. Mortality occurred in 2 male infants because of myocardial infarction, which corroborates a more severe outcome in male infants, as reported previously. ${ }^{26-36}$

A remarkable finding of our study is that the incidence rate is related to the population density, which varies throughout the country. Differences in the incidence of KD were found to occur between

TABLE 3. Incidence of Kawasaki Disease in Portuguese Population Stratified by Gender and Age Groups and Subgroups

\begin{tabular}{|c|c|c|c|c|c|c|c|c|c|c|}
\hline \multirow[b]{2}{*}{ Year } & \multicolumn{5}{|c|}{ Male } & \multicolumn{5}{|c|}{ Female } \\
\hline & $<1 \mathrm{yr}$ & $1-4 \mathrm{yr}$ & $5-9$ yr & $10-14 \mathrm{yr}$ & $15-19 \mathrm{yr}$ & $<1 \mathrm{yr}$ & $1-4 \mathrm{yr}$ & $5-9 \mathrm{yr}$ & $10-14 \mathrm{yr}$ & $15-19 \mathrm{yr}$ \\
\hline 2000 & 8.92 & 8.04 & 0.75 & 0.36 & 0.00 & 9.61 & 7.04 & 0.79 & 0.38 & 0.00 \\
\hline 2001 & 7.28 & 6.02 & 0.38 & 0.00 & 0.00 & 5.86 & 1.48 & 2.40 & 0.00 & 0.00 \\
\hline 2002 & 14.35 & 4.12 & 1.51 & 0.00 & 0.00 & 3.85 & 4.39 & 0.40 & 0.00 & 0.00 \\
\hline 2003 & 7.31 & 5.44 & 2.28 & 0.00 & 0.00 & 3.92 & 0.97 & 1.21 & 0.00 & 0.35 \\
\hline 2004 & 26.53 & 7.75 & 0.75 & 0.37 & 0.00 & 7.99 & 4.38 & 0.80 & 0.38 & 0.00 \\
\hline 2005 & 9.39 & 7.46 & 1.86 & 0.00 & 0.00 & 6.03 & 3.96 & 2.35 & 0.00 & 0.00 \\
\hline 2006 & 9.84 & 5.17 & 1.11 & 0.00 & 0.00 & 10.31 & 3.99 & 0.00 & 0.39 & 0.00 \\
\hline 2007 & 14.14 & 8.16 & 1.48 & 0.38 & 0.00 & 8.52 & 5.06 & 0.00 & 0.00 & 0.00 \\
\hline 2008 & 11.88 & 7.89 & 1.11 & 0.38 & 0.00 & 4.19 & 8.79 & 0.00 & 0.40 & 0.00 \\
\hline 2009 & 8.38 & 4.49 & 1.88 & 0.00 & 0.00 & 6.53 & 9.36 & 0.79 & 0.00 & 0.00 \\
\hline 2010 & 6.22 & 8.80 & 0.00 & 0.00 & 0.00 & 2.12 & 3.80 & 0.82 & 0.00 & 0.38 \\
\hline 2011 & 12.92 & 9.97 & 1.18 & 0.37 & 0.00 & 9.05 & 4.37 & 1.66 & 0.00 & 0.00 \\
\hline Total & 11.43 & 6.94 & 1.19 & 0.15 & 0.00 & 6.50 & 4.71 & 0.94 & 0.13 & 0.06 \\
\hline
\end{tabular}


TABLE 4. Prevalence of Kawasaki Disease in Portuguese Population Stratified by Region and Year

\begin{tabular}{cccccc}
\hline \hline & \multicolumn{5}{c}{ Incidence per 100,000 Children } \\
\cline { 2 - 6 } Year & Alentejo & Algarve & Center & Lisbon & North \\
\hline 2000 & 0.64 & 1.22 & 0.98 & 6.62 & 0.33 \\
2001 & 0.65 & 2.40 & 0.60 & 3.56 & 0.44 \\
2002 & 0.66 & 2.37 & 1.63 & 3.01 & 0.56 \\
2003 & 0.67 & 2.34 & 0.83 & 3.17 & 0.57 \\
2004 & 1.36 & 3.48 & 1.89 & 4.75 & 1.05 \\
2005 & 0.00 & 2.28 & 1.48 & 4.38 & 1.07 \\
2006 & 0.69 & 1.12 & 1.71 & 4.01 & 0.00 \\
2007 & 0.70 & 2.21 & 1.08 & 4.50 & 1.10 \\
2008 & 0.00 & 0.00 & 1.96 & 3.78 & 1.86 \\
2009 & 0.70 & 2.14 & 1.76 & 3.77 & 0.76 \\
2010 & 0.71 & 0.00 & 1.35 & 2.74 & 1.03 \\
2011 & 0.00 & 2.18 & 2.30 & 4.14 & 1.18 \\
Total & 0.57 & 1.81 & 1.46 & 4.03 & 0.83 \\
\hline
\end{tabular}

different territorial regions of Portugal, with the highest incidences found in the most densely populated provinces. Urbanization, industrialization and higher socioeconomic status have previously been suggested to be related to the occurrence of $\mathrm{KD}$, which may be related to important sociocultural differences between the highly populated areas, such as Lisbon, and the agricultural regions in Portugal, like the northern and the southern ones. It is also possible that differences in incidences between territories could be because of differences in scientific awareness about $\mathrm{KD}$ diagnosis that prevails in these territories

This study has some limitations. The number of KD-associated hospitalizations could have been underestimated because of inclusion of misdiagnosed cases as KD or no inclusion of cases that were not hospitalized. Some data were unavailable, such as race/ ethnicity, clinical characteristics, like duration of fever, therapeutics or other complications that might not have been coded. ${ }^{37}$

A unique feature of this study was the use of the national database of DRG classification system. This national database of hospitalized patients, with coded diagnosis and procedures, is in use in Portugal since 1990, is mandatory for all hospital discharged patients. The use of these data was demonstrated in other studies as adequate to generate solid national estimates of hospitalizations of both rare and common diseases in all age groups, representing an important tool for epidemiologic studies to estimate national hospitalization data ${ }^{10,23,28,32,37}$. The usefulness and adequacy of this methodology to estimate KD epidemiology in Portugal was demonstrated.

The epidemiologic data reported by this study is consistent with similar European studies on Caucasians, specifically the predilection for younger children and male predominance. As the first Portuguese study, it might serve as a useful tool for further clinical and epidemiologic studies.

\section{ACKNOWLEDGMENTS}

We thank Professor Paulo Nogueira, from Direcção Geral de Saúde-Statistics Department; Helena Aidos and André Lourenço, for statistical assistance, and Vanessa Rodrigues for collaboration in the interpretation of the coded database.

\section{REFERENCES}

1. Kawasaki T, Kosaki F, Okawa S, et al. A new infantile acute febrile mucocutaneous lymph node syndrome prevailing in Japan. Paediatrics. 1974;54:271-276

2. Bradley DJ, Glodé MP. Kawasaki disease: the mystery continues. West $J$ Med. 1998;168:23-29.

3. Curtis N, Levin M. Kawasaki disease thirty years on. Curr Opin Pediatr. 1998; 10:24-33.
4. Rowley AH, Shulman ST. Kawasaki syndrome. Clin Microbiol Rev. 1998;11:405-414.

5. Taubert KA, Rowley AH, Shulman ST. A 10-year (1984-1993) United States hospital survey of Kawasaki disease. In: Kato H, ed. Kawasaki Disease. Amsterdam, The Netherlands: Elsevier Science; 1995:34-38.

6. Morens DM, Anderson LJ, Hurwitz ES. National surveillance of Kawasaki disease. Pediatrics. 1980;65:21-25.

7. Bell DM, Morens DM, Holman RC, et al. Kawasaki syndrome in the United States 1976 to 1980. Am J Dis Child. 1983;137:211-214.

8. Rauch AM. Kawasaki syndrome: review of new epidemiologic and laboratory developments. Pediatr Infect Dis J. 1987;6:1016-1021.

9. Burgner D, Harnden A. Kawasaki disease: what is the epidemiology telling us about the etiology? Int J Infect Dis. 2005;9:185-194.

10. Taubert KA. Epidemiology of Kawasaki disease in the United States and worldwide. Prog Pediatr Cardiol. 1997;6:181-185.

11. Nakamura Y, Yashiro M, Uehara R, et al. Epidemiologic features of Kawasaki disease in Japan: results of the 2009-2010 nationwide survey. J Epidemiol. 2012;22:216-221.

12. Park YW, Han JW, Hong YM, et al. Epidemiological features of Kawasaki disease in Korea, 2006-2008. Pediatr Int. 2011;53:36-39.

13. Huang WC, Huang LM, Chang IS, et al; Kawasaki Disease Research Group. Kawasaki Disease Research Group. Epidemiologic features of Kawasaki disease in Taiwan, 2003-2006. Paediatrics. 2009;123:e401-e405.

14. Lemos L, Pinto L, Zamith D, et al. Três casos de doença de Kawasaki ou síndrome adeno-cutâneo-mucoso agudo febril. Uma afecção que os Pediatras e Clínicos Gerais devem conhecer. Rev Port Pediatr. 1981;12:167-174.

15. Proença R, Sousa M, Vakil K, et al. A case of Kawasaki disease in Portugal. Acta Med Port. 1983;4:97-99.

16. Gouveia C, Brito M, Ferreira G, et al. Doença de Kawasaki - Casuística do Hospital Fernando da Fonseca. Rev Port Cardiol. 2005;24:1097-1113.

17. Pereira A, Silva A, Álvares S. Síndrome de Kawasaki: experiência da consulta de cardiologia pediátrica do Hospital Maria Pia. Nascer e Crescer. 2000;9:96-100.

18. Lima M, Kaku SS, Agualusa A, et al. Alterações cardiovasculares na doença de Kawasaki. Rev Port Pediatr. 1989;20:419-426.

19. Lima M, Kaku S, Macedo A, et al. Echocardiographic diagnosis and surgical treatment of giant coronary arterial aneurysms. In: Takahashi M, Taubert $\mathrm{K}$, eds. Proceedings of the Fourth International Symposium on Kawasaki Disease. Dallas, TX: American Heart Association; 1993:404-407.

20. Santos V, Simões AS, Teixeira A, et al. Cirurgia de revascularização coronária após doença de Kawasaki. Rev Port Cardiol. 2012;31:433.

21. Yanagawa H, Nakamura Y, Yashiro M, et al. Incidence survey of Kawasaki disease in 1997 and 1998 in Japan. Pediatrics. 2001;107:E33.

22. Public Health Service and Health Care Financing Administration. International Classification of Diseases, 1997, Ninth Revision, Clinical Modification. 6th ed. (CD-ROM). Washington, DC: Department of Health and Human Services; 1998.

23. Holman RC, Belay ED, Curns AT, et al. Kawasaki syndrome hospitalizations among children in the United States, 1988-1997. Paediatrics. 2003; $111: 448$

24. Huang SK, Lin MT, Chen HC, et al. Epidemiology of Kawasaki disease: prevalence from national database and future trends projection by system dynamics modeling. J Pediatr. 2013;163:126-131.e1.

25. Instituto Nacional de Estatística, I.P. Av. António José de Almeida 1000-043. Censos 2011 Portugal Resultados. 2012. Lisboa, Portugal. Available at: http:// censos.ine.pt/xportal/xmain?xpid=CENSOS\&xpgid=ine_censos_publicacao_ det $\&$ contexto=pu\&PUBLICACOESpub_boui $=73212469 \&$ PUBLICACOES modo $=2 \&$ selTab $=$ tab1\&pcensos $=61969554$. Accessed January 10, 2016.

26. Uehara R, Belay ED. Epidemiology of Kawasaki disease in Asia, Europe, and the United States. J Epidemiol. 2012;22:79-85.

27. Salo E, Griffiths EP, Farstad T, et al. Incidence of Kawasaki disease in northern European countries. Pediatr Int. 2012;54:770-772.

28. Harnden A, Alves B, Sheikh A. Rising incidence of Kawasaki disease in England: analysis of hospital admission data. BMJ. 2002;324:1424-1425.

29. Fischer TK, Holman RC, Yorita KL, et al. Kawasaki syndrome in Denmark. Pediatr Infect Dis J. 2007;26:411-415.

30. Salo E. Kawasaki disease in Finland in 1982-1992. Scand J Infect Dis 1993;25:497-502.

31. Sanchez-Manubens J, Jordi A, Prada F, et al. Incidence and clinical features of Kawasaki disease in Catalonia (Spain). Pediatr Rheumatol Online J. 2014;12(suppl 1):P123. 
32. Lynch M, Holman RC, Mulligan A, et al. Kawasaki syndrome hospitalizations in Ireland, 1996 through 2000. Pediatr Infect Dis J. 2003;22:959-963.

33. Tamburlini G, Strinati R, Cadorini S, et al. A two-year survey of mucocutaneous lymph node syndrome in northeastern Italy. Epidemiological and clinical findings. Helv Paediatr Acta. 1984;39:319-329.

34. Falcini F, Cimaz R, Calabri GB, et al. Kawasaki disease in Northern Italy: a multicenter data collection of 250 patients. Clin Exp Rheumatol. 2002;20:421-426

35. Dhillon R, Newton L, Rudd PT, et al. Management of Kawasaki disease in the British Isles. Arch Dis Child. 1993;69:631-638.

36. Royle JA, Williams K, Elliott E, et al. Kawasaki disease in Australia, 199395. Arch Dis Child. 1998;78:33-39.

37. Dixon J, Sanderson C, Elliott P, et al. Assessment of the reproducibility of clinical coding in routinely collected hospital activity data: a study in two hospitals. J Public Health Med. 1998;20:63-69.
38. Harnden A, Mayon-White R, Perera R, et al. Kawasaki disease in England: ethnicity, deprivation, and respiratory pathogens. Pediatr Infect Dis J. 2009;28:21-24.

39. Heuclin T, Dubos F, Hue V, et al; Hospital Network for Evaluating the Management of Common Childhood Diseases. Increased detection rate of Kawasaki disease using new diagnostic algorithm, including early use of echocardiography. J Pediatr. 2009;155:695-699.e1.

40. Olafsdottir HS, Oskarsson G, Haraldsson Á. [Kawasaki disease in Iceland 1996-2005, epidemiology and complications]. Laeknabladid. 2012;98:9195

41. Tamburlini G, Strinati R. Kawasaki disease in north-east Italy. Lancet 1983;1:822-823.

42. Tacke CE, Breunis WB, Pereira RR, et al. Five years of Kawasaki disease in the Netherlands: a national surveillance study. Pediatr Infect Dis J. 2014;33:793-797.

\section{ERRATUM}

Update on Zika: What You Need to Know: ERRATUM

In the article on page 333, volume 36, issue 3, the incorrect version of Figure 1 was included. The final and author-approved version of Figure 1 appears below.

\section{New detection of mosquito-borne Zika virus infections, 2013 - 2016}

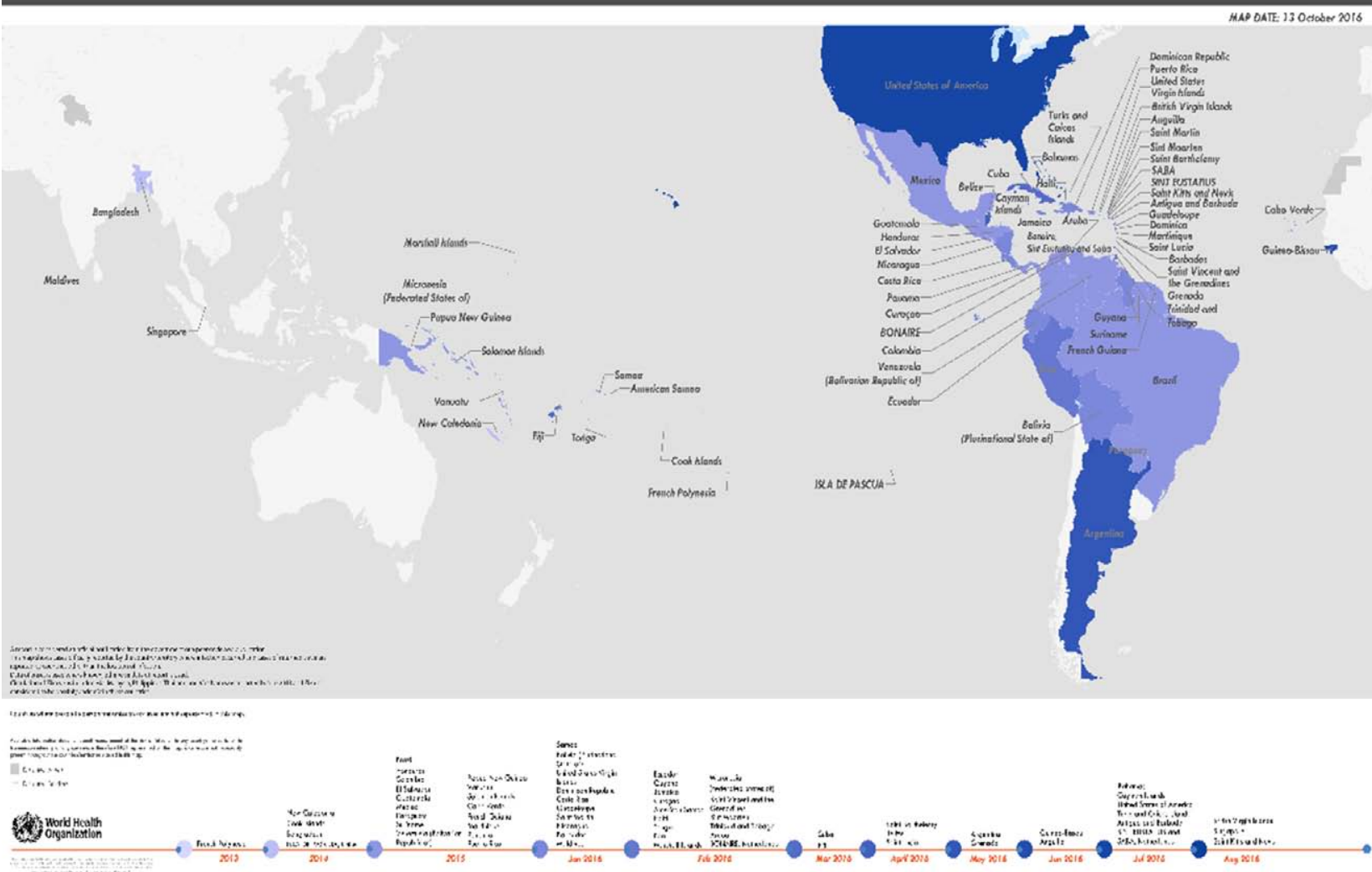

FIGURE 1. Countries, territories and areas showing the distribution of Zika virus, 2013-2016. $\frac{\text { full color }}{0 \text { lin }}$

\section{REFERENCE}

Sáfadi MAP, Nascimento-Carvalho C. Update on Zika: What you need to know. Pediatr Infect Dis J. 2017;36:333-336. 